\title{
Microstructure of Complex Silicon-containing Modifier
}

\author{
V.P. Ermakova1, V.G. Smirnova1, S.Yu. Melchakov¹, V.V. Kataev", \\ L.A. Ovchinnikova ${ }^{1}$, L.A. Marshuk ${ }^{1}$, and O.Yu. Sheshukov ${ }^{1,2}$ \\ ${ }^{1}$ Institute of Metallurgy of Ural Branch of Russian Academy of Sciences, 101, Amundsen Street, \\ Ekaterinburg, Russia, 620016 \\ ${ }^{2}$ Ural Federal University named after the first President of Russia B.N. Yeltsin, 19, Mira Street, \\ Ekaterinburg, Russia, 620016
}

\section{Abstract}

Various research methods show that the microstructure of the complex siliconcontaining modifier "Insteel 7" consists of six phases: $\mathrm{TiFeSi}_{2}, \mathrm{Ca}_{1-x}(\mathrm{La}, \mathrm{Ce})_{x} \mathrm{Si}_{2}, \mathrm{CaSi}_{2}$, $\mathrm{FeSi}_{2}$ and a phase based on $\mathrm{BaSi}_{2}$, containing impurities of $\mathrm{Ca}, \mathrm{Si}, \mathrm{Al}$, and $\mathrm{Mg}$. Silicides of titanium, iron, calcium, and barium in the composition of the modifier due to their low melting points contribute dissolution of Insteel 7 and enhance the effect of the modification when introduced into the liquid metal. In addition, the phases containing

Corresponding Author:

S.Yu. Melchakov

s.yu.melchakov@gmail.com

Received: 5 February 2019

Accepted: 6 March 2019

Published: 17 March 2019

Publishing services provided by Knowledge E

(c) V.P. Ermakova et al. This article is distributed under the terms of the Creative Commons Attribution License, which permits unrestricted use and redistribution provided that the original author and source are credited.

Selection and Peer-review under the responsibility of the NIOKR-2018 Conference Committee.

\section{G OPEN ACCESS} rare earth metals can purify the metal from harmful impurities and reduce the content of dissolved gases $(\mathrm{O}, \mathrm{N})$ and sulfur when they enter the steel melt. TiCN particles with a melting point of $3200^{\circ} \mathrm{C}$ can serve as inoculators, because they act as crystallization centers after being added to the molten metal. They contribute to obtaining an equiaxed or close to an equiaxial grain structure of alloys in the solid state.

Keywords: complex silicon-containing modifier, microstructure, phase composition

\section{Introduction}

It is known [1-3] that the modification of cast iron and steel is a flexible and highly efficient method for controlling the structure of iron-based alloys. Modifiers introduced into the molten metal provide the appearance of additional centers of crystallization, leading to the formation of a homogeneous and fine-grained structure of the alloys in the solid state. So far, there is no common understanding [4] of the mechanism of the modification process. Besides, there is no assessment of the modifying (inoculation) ability of individual elements. This is especially important in the case of the using of complex modifiers containing inoculants with different physicochemical nature and properties. Moreover, the technical performance of the modifier is mainly determined by the content in it of chemically active elements - rare earth metals (REM), Ca, Ti etc. [5, 6]. For example, it is known [7] that rare-earth metals actively interact with oxygen, sulfur 
and nitrogen, providing a significant decrease in the content of these impurities in the molten metal. Besides is known $[4,8,9]$ that titanium can form insoluble or hardly soluble particles of titanium nitride, carbide or titanium carbonitride in the modifier composition (since titanium carbide and titanium nitride have complete mutual solubility [4]). Titanium carbides, nitrides and carbonitrides are present in the modifier due to their high melting temperature $\left(\mathrm{TiC}-3140^{\circ} \mathrm{C}, \mathrm{TiN}-2959^{\circ} \mathrm{C}, \mathrm{TiCN} \sim 2500-3000^{\circ} \mathrm{C}\right)$. They can serve, in our opinion, as crystallization centers during the solidification of the melt. Some researchers $[4,9]$ also recognize that refractory nitrides and titanium carbonitrides play a role in the inoculation mechanism.

The authors of [10] believe that the structure of complex modifiers is practically not studied. There are almost no investigations on the effect of the structure of modifiers on the properties of the melt being processed and the solid metal. A recent trend in metallurgy is metallography of modifiers [11]. This field of knowledge can provide, in our opinion, useful information on the composition and structure of the modifiers and will allow us to evaluate the abilities of the modifiers after introducing into the melts.

Researchers $[12,13]$ believe that the effectiveness of the modification is determined, as a rule, by the phase composition, shape, and size of the structural components (phases) and their distribution in the modifier volume. In work [12], is emphasized that the introduction of fine-crystalline modifiers into the steel structure provides more uniform distribution of small phases containing chemically active elements of rare-earth metals, alkaline earth metals, $\mathrm{Ti}$, etc.

It is known [14] that a change of crystallization speed of a modifier leads to a change in the size, composition, and distribution of structural components in it. It is important to consider the size of structural components (phases) with low melting points and the size of the modifier particles introduced into alloy melt, when fast instant modifiers [15] are applied. But, when the inoculating effect is required, these parameters are not so significant, since the more essential characteristic of the modifier will be determined by the melting point of the phases present in it.

The question of the correct determination of the modifier phase composition is a key one since it makes possible to correctly evaluate the modifying (inoculating) ability of individual elements (phases) and their influence on the structure of the modified cast steel.

The purpose of this work is to determine the chemical and mineralogical nature (morphology and composition) of the structural components (phases) of the Insteel 7 complex microcrystalline modifier, comparing the results of optical and electron microscopy, EDX, and XRD-analysis 


\section{Samples and Experimental Technique}

According to the results of chemical analysis the Insteel 7 complex microcrystalline silicon-containing modifier consists of following elements (wt.\%): $\mathrm{Si}$ (42.5\%), Ti (13.5\%), Ca (10.3\%), Ba (8.7\%), Mg (0.8\%), Ce (3.3\%), La (2.4\%)), N (0.5\%), O (0.18\%), C (0.36\%), Fe the rest.

The following instruments were used to identify phases in the modifier:

1. Neophot-2 - an optical microscope equipped with a digital video camera and a Siams-700 computer image analysis system;

2. Carl Zeiss EVO 40 scanning electron microscope with a device for electron probe X-ray microanalysis (EDX), equipped with an Inca X-Act Oxford Instruments SDD spectrometer and a system for energy-dispersive microanalysis Inca Energy SEM;

3. X-ray diffractometer SHIMADZU XRD 7000, equipped with a $\mathrm{Cu} \mathrm{K} \alpha$ filter in a graphite monochromator and automatic software for $\mathrm{X}$-ray structural phase analysis (XRD). For deciphering the XRD patterns the literature data, the ICDD (International Center for Diffraction Data), the PDF-2 database, and the JCPDS files were used;

4. Chemical analysis of the modifier was performed using the SpectroFlame Modula S and Optima 2100 DV atomic emission spectrometers with inductively coupled plasma. The content of carbon in the modifier was determined on a Leco CS-230 device.

\section{Results and Discussion}

The Insteel 7 complex modifier is intended for introducing into Fe-C-based melts in order to control their microstructure.

The microstructure of the Insteel 7 modifier is presented in Figure 1.

The optical properties and morphology of irregular-shaped grey-pink inclusions in Figure 1 allowed us to conclude that they are titanium carbonitrides -TiCN [16].

Since it was not possible to determine other phases of the modifier by optical microscopy, therefore the material was sent to the X-ray diffraction analysis. The typical XRD pattern of the Insteel 7 modifier is shown in Figure 2.

Using the XRD method, we did not fix particles of grey-pink TiCN phase as part of the modifier, apparently, because of its small amount and complexity of the observed spectrum. In addition, it was found that the reflections of other possible phases, for example, 


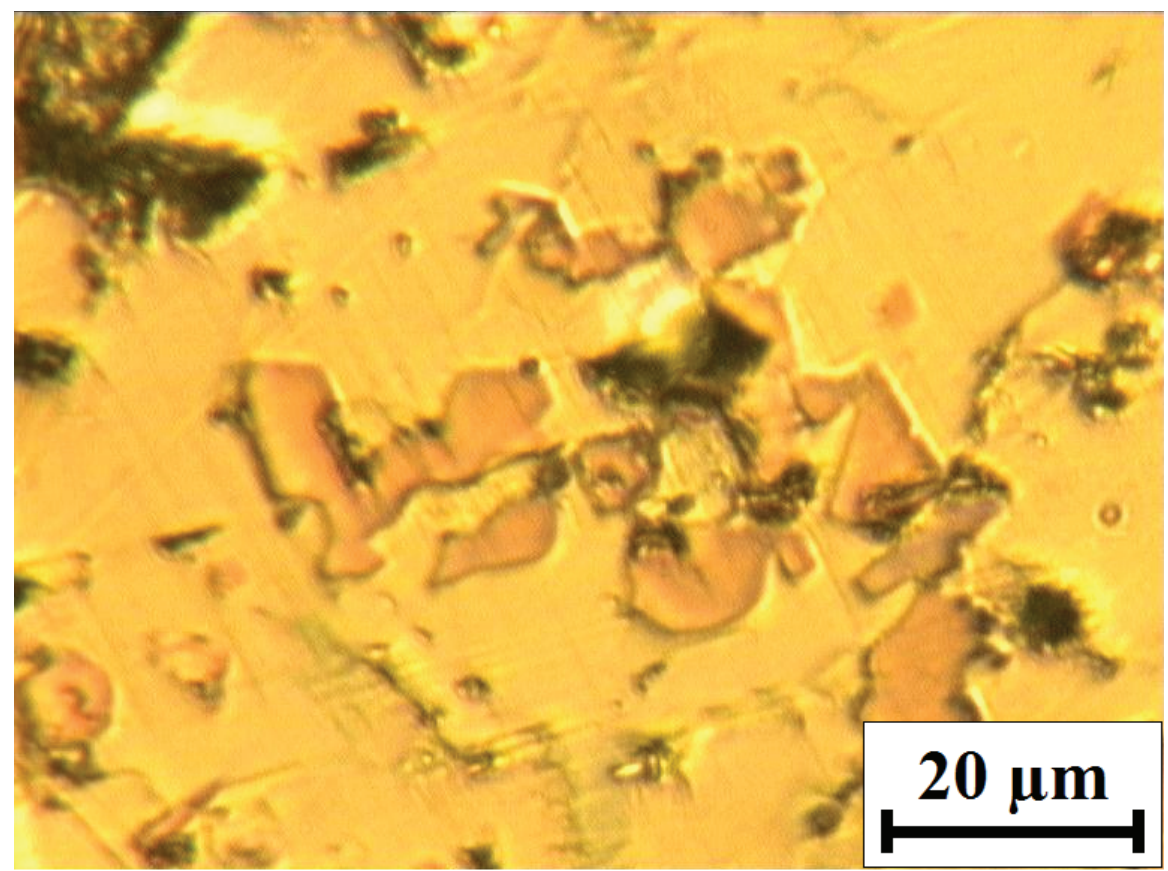

Figure 1: The microstructure of the Insteel 7 modifier in the light field of an optical microscope.

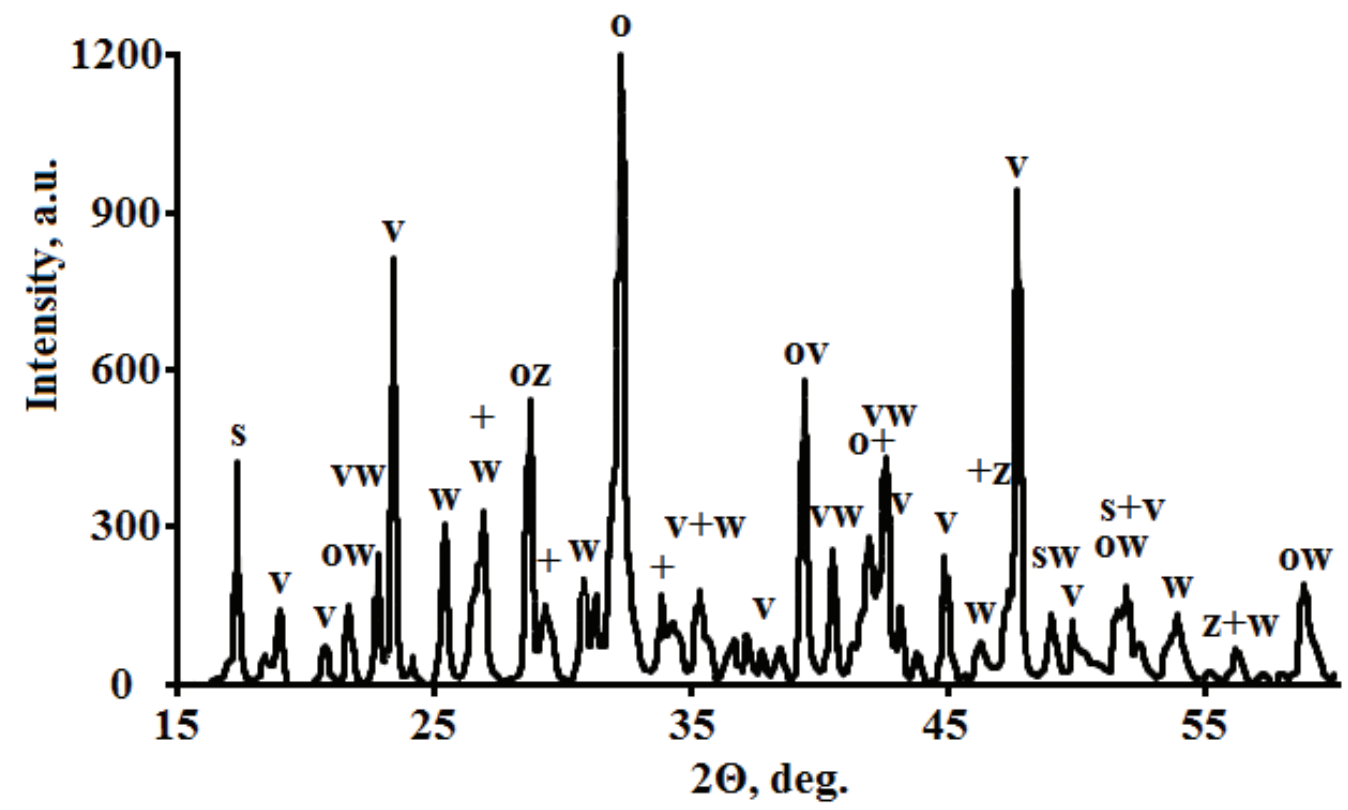

Figure 2: The XRD pattern of the Insteel 7 complex modifier. Symbols denote: $0-\mathrm{Ca}_{0.8} \mathrm{La}_{0.2} \mathrm{Si}_{2} ; \mathrm{s}-\alpha-\mathrm{FeSi}_{2}$; $+-\mathrm{CaSi}_{2} ; \mathrm{v}-\mathrm{TiFeSi}_{2} ; \mathrm{w}-$ phase based on $\mathrm{BaSi}_{2} ; \mathrm{z}-\mathrm{Si}$.

elemental silicon, aluminum and magnesium compounds found by chemical analysis, are superimposed on the reflections of the multicomponent phase based on $\mathrm{BaSi}_{2}$, as well as on the $\mathrm{FeSi}_{2}$ and $\mathrm{CaSi}_{2}$ phases. Besides, there are no observing reflections from cerium-containing compounds on the diffractogram. 
For complete identification of the phases in the material under study we have summarized in Table 1 the crystallographic data of the phases in the modifier.

From Table 1 it seems that the complex modifier can consist of six types of structures differing in crystal lattices: $\mathrm{TiFeSi}_{2}$, rhombohedral $\mathrm{CaSi}_{2}, \alpha-\mathrm{FeSi}_{2}, \mathrm{BaSi}_{2}, \mathrm{TiCN}$, and phases with a common type of $\mathrm{ThSi}_{2}$ lattice - calcium, lanthanum and cerium silicide.

We assumed that the presence of the same structural type, space groups, and very close lattice parameters for lanthanum, cerium, and calcium silicides can lead to the formation of solid solutions in the $\mathrm{CaLnSi}_{2}(\mathrm{Ln}=\mathrm{La}, \mathrm{Ce})$ compositions. Therefore they can be conventionally represented as $\mathrm{Ca}_{1-x}(\mathrm{Ce}, \mathrm{La})_{x} \mathrm{Si}_{2}$. This is indirectly indicated by the reflections recorded on the XRD pattern that are very similar in structure and composition to the $\mathrm{Ca}_{0.8} \mathrm{La}_{0.2} \mathrm{Si}_{2}$ phase, in which the angles $2 \theta$ and interplanar spacings are well suited to the reflections of the phase we expected.

Our assumption about the formation of solid solutions in Ca-Ln-Si systems has been confirmed by other researchers. So the authors of work [17] found a phase with similar composition - $\mathrm{Ca}_{1-x} \mathrm{La}_{x} \mathrm{Si}_{2}$. The parameter " $x$ " for this compound can vary over a wide range -0.2 ...1.0 while the crystal structure of the solid solution preserves. The authors of [17] believe that in compounds of the $\mathrm{Ca}_{1-x} \mathrm{Me}_{x} \mathrm{Si}_{2}$ type, $\mathrm{Sr}, \mathrm{Y}, \mathrm{Nd}, \mathrm{La}, \mathrm{Ce}, \mathrm{Pr}, \mathrm{Sm}, \mathrm{Eu}$, Gd, Dy and Th atoms can also act as metal atoms (Me) replacing calcium.

The proximity of the ionic radii and thermodynamic properties of the listed rare metals means that ternary Ca-Ln-Si systems ( $\mathrm{Ln}=\mathrm{La}$, Ce, Pr, Sm, Eu, Gd, Dy) can form compounds of variable composition (solid solutions) of the type $\mathrm{Ca}_{1-x}\left(\mathrm{Ln}_{1}, \mathrm{Ln}_{2}\right)_{x} \mathrm{Si}_{2}$ with a very wide range of concentrations of rare earth metals.

According to the literature [18-20], $\mathrm{CaSi}_{2}$ depending on the external pressure forms two types of crystal lattices. At a pressure equal to atmospheric, $\mathrm{CaSi}_{2}$ forms crystals with a rhombohedral elementary cell, in which the atoms of silicon and calcium are arranged in the form of alternating layers. A modification of $\mathrm{CaSi}_{2}$ formed at high pressures has crystals with a tetragonal syngony and an $\alpha-\mathrm{ThSi}_{2}$ type lattice [17]. Due to the fact that $\mathrm{CaSi}_{2}$ with a rhombohedral elementary cell structure was found in the complex modifier, it was concluded that the complex modifier was fused and poured at atmospheric pressure.

The formation of the $\mathrm{Ca}_{1-x}(\mathrm{Ce}, \mathrm{La})_{x} \mathrm{Si}_{2}$ phase seems to be related to the fact that during the smelting of the modifier, disilicides of rare-earth metals and excess calcium disilicide were initially introduced into its melt. During crystallization part of $\mathrm{CaSi}_{2}$ became as the basis for solid solution enriched with La and Ce. And an excess of calcium disilicide has formed a single phase with a rhombohedral lattice. 
TABLE 1: Crystallographic data of phases in Insteel 7 complex silicon-containing modifier.

\begin{tabular}{|c|c|c|c|c|c|c|}
\hline \multirow[t]{2}{*}{ Composition } & \multirow[t]{2}{*}{ Proto-type } & \multirow[t]{2}{*}{ Syngony } & \multirow[t]{2}{*}{ Space group } & \multicolumn{3}{|c|}{ Lattice parameters, nm } \\
\hline & & & & $\mathbf{a}$ & b & c \\
\hline $\mathrm{TiFeSi}_{2}$ & $\mathrm{TiMnSi}_{2}$ & orthorhombic & Pbam (55) & 0.8605 & 0.9521 & 0.7644 \\
\hline $\mathrm{CaSi}_{2}$ & $\mathrm{CaSi}_{2}$ & rhomhedral & $R-3 m(166)$ & 0.3855 & - & 3.061 \\
\hline $\mathrm{CaSi}_{2}$ & $\mathrm{ThSi}_{2}$ & tetragonal & I41/amd(141) & 0.4283 & - & 1.352 \\
\hline $\mathrm{LaSi}_{2}$ & $\mathrm{ThSi}_{2}$ & tetragonal & I41/amd(141) & 0.4281 & - & 1.375 \\
\hline $\mathrm{CeSi}_{1.9}$ & $\mathrm{ThSi}_{2}$ & tetragonal & I41/amd(141) & 0.4198 & - & 1.389 \\
\hline $\mathrm{Ca}_{0,8} \mathrm{La}_{0,2} \mathrm{Si}_{2}$ & $\mathrm{ThSi}_{2}$ & tetragonal & I41/amd(141) & 0.431 & - & 1.350 \\
\hline$\alpha-\mathrm{FeSi}_{2}$ & $\mathrm{GdSn}_{3}$ & orthorhombic & Cmca(64) & 0.988 & 0.7798 & 0.7839 \\
\hline $\mathrm{BaSi}_{2}$ & $\mathrm{BaSi}_{2}$ & orthorhombic & Pnma(62) & 0.8863 & 0.6697 & 1.156 \\
\hline $\mathrm{TiCN}$ & No data & cubic & $F m-3 m(225)$ & 0.4276 & - & - \\
\hline
\end{tabular}

The phase based on barium disilicide has a high silicon content - the atomic ratio $\mathrm{Si}$ / $\mathrm{Ba} \approx 5$ (Table 2 ). Such a ratio of silicon to barium $[21,22]$ is possible only at elevated pressure and temperature. Since the complex modifier was prepared and poured, apparently, at atmospheric pressure, we believe that this phase is a multicomponent, which is based on barium disilicide, elemental silicon, as well as traces of impurity metals aluminum and magnesium.

Additional information on the composition and structure of the phases of the Insteel 7 modifier was obtained using the SEM-EDX methods (Table 2). The microstructure of the modifier in backscattered electrons is shown in Figure 3.

TABLE 2: The results of EDX-analysis of phases in the Insteel 7 modifier.

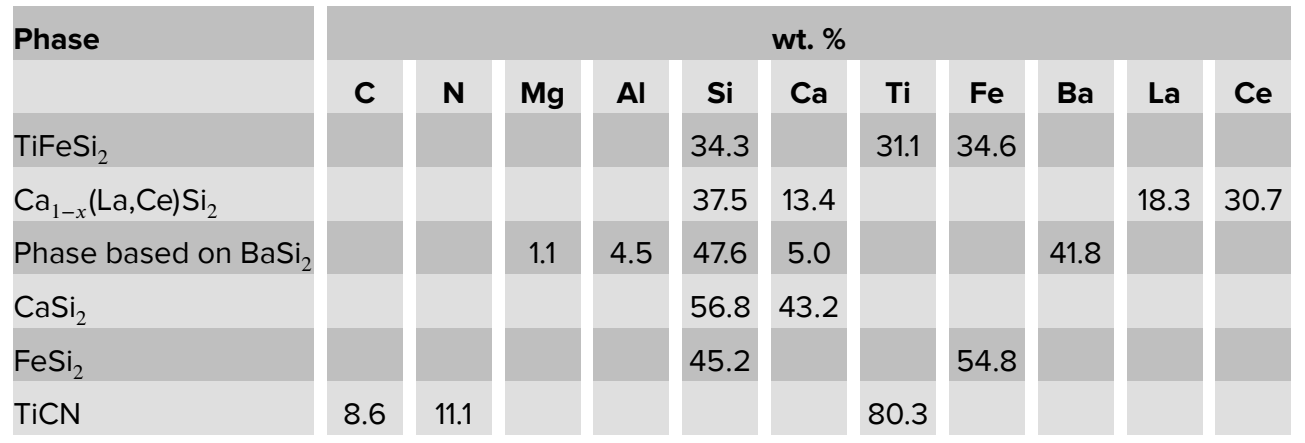

As seen from the Table 2, EDX-analysis confirms our assumption that modifier contains the $\mathrm{Ca}_{1-x}(\mathrm{Ce}, \mathrm{La})_{x} \mathrm{Si}_{2}$ composition and the TiCN phase.

A comparative analysis of the results of XRD and EDX shows that the Insteel 7 complex silicon-containing modifier contains six phases: $\mathrm{TiFeSi}_{2}, \alpha-\mathrm{FeSi}_{2}, \mathrm{CaSi}_{2}, \mathrm{Ca}_{1-x}(\mathrm{La}, \mathrm{Ce})_{x} \mathrm{Si}_{2}$, TiCN and a complex multicomponent phase based on $\mathrm{BaSi}_{2}$ with unbound $\mathrm{Si}$, and $\mathrm{Ca}$, $\mathrm{Al}, \mathrm{Mg}$ impurities. 


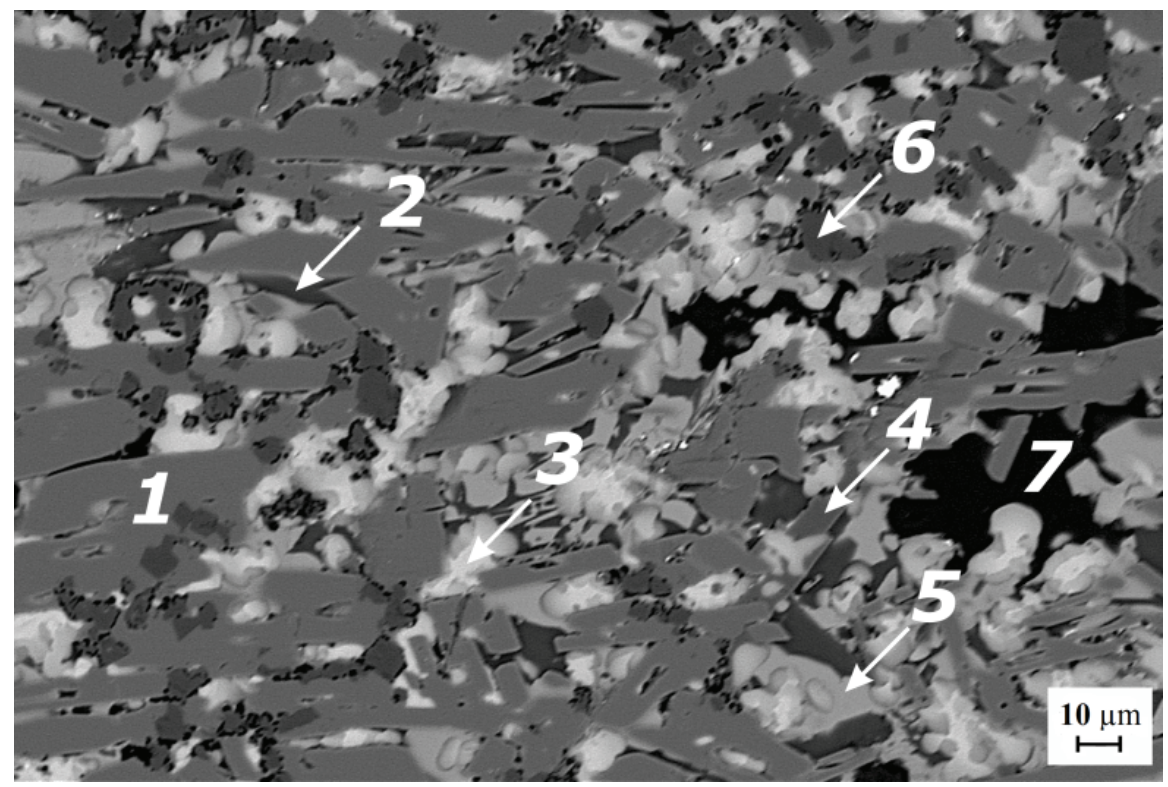

Figure 3: SEM-image of the microstructure of the Insteel 7 modifier: $1-\mathrm{TiFeSi}_{2} ; 2-\mathrm{CaSi}_{2} ; 3-$ $\mathrm{Ca}_{1-x}(\mathrm{La}, \mathrm{Ce})_{x} \mathrm{Si}_{2} ; 4-\mathrm{FeSi}_{2} ; 5$ - phase based on $\mathrm{BaSi}_{2}$, with impurities of $\mathrm{Si}, \mathrm{Ca}, \mathrm{Ba}, \mathrm{Al}$ and $\mathrm{Mg} ; 6$ - TiCN; 7 - pore.

\section{Conclusion}

1. The employment of various research methods made it possible to clarify that the Insteel 7 complex silicon-containing modifier consists of six phases: $\mathrm{TiFeSi}_{2}$, $\mathrm{Ca}_{1-x}(\mathrm{La}, \mathrm{Ce})_{x} \mathrm{Si}_{2}, \mathrm{CaSi}_{2}, \mathrm{FeSi}_{2}, \mathrm{TiCN}$ and a phase based on $\mathrm{BaSi}_{2}$, containing $\mathrm{Si}$ and impurities of $\mathrm{Ca}, \mathrm{Al}$ and $\mathrm{Mg}$.

2. Titanium, iron, calcium and barium silicide in the composition of the modifier due to their low melting points and unlimited solubility of silicon in iron facilitate the dissolution of the modifier, reinforcing the effect of modifying when modifier is entering into the liquid metal.

3. The $\mathrm{Ca}_{1-x}(\mathrm{La}, \mathrm{Ce})_{x} \mathrm{Si}_{2}$ phase after introducing into the steel melts is able to reduce the content of dissolved gases $(\mathrm{O}, \mathrm{N})$ and Sulphur in the metal.

4. Particles of $\mathrm{TiCN}\left(\mathrm{T}_{\text {melt }}=3200^{\circ} \mathrm{C}\right)$ can serve as inoculators, i.e., act as crystallization centers after the introduction into the molten metal and promote receipt of an equiaxial or close to an equiaxial grain structure of alloys in the solid state.

The work was performed as part of the State topic "Structural, physicochemical and mechanical properties of aluminum and copper alloys and composites for structural and electrical purposes" (No. 0396-2015-0078) using the equipment of the "Ural-M" Collective Use Center. 


\section{References}

[1] Goldstein, Ya.E. and Mizin, V.G. (1986). Modifying and micro-alloying of cast iron and steel. Moscow: Metallurgiya (in Russian).

[2] Sheshukov, O.Yu. (2012). Structure of modifier and properties of cast iron, in Proceedings of the $1^{\text {st }}$ International Interactive scientific and practical conference: Innovations in materials science and metallurgy. Yekaterinburg: Izdatelstvo Uralskogo universiteta. (in Russian).

[3] Ryabchikov, I.V. (2005). The history of the development of the modifiers production and the basic requirements for them, in Collection of reports of the Foundry Consulium No.1: Modification as an effective method of improving the quality of cast iron and steel. Chelyabinsk: Chelyabinskiy Dom pechati. (in Russian).

[4] Goldstein, Ya.E. and Mizin, V.G. (1993). Inoculation of Fe-C alloys. Moscow: Metallurgiya. (in Russian).

[5] Shub, L.G. and Akhmadeyev, A.Yu. About the advisability of cast steel modifying, in Collection of reports of the Foundry Consulium No.1: Modification as an effective method of improving the quality of cast iron and steel. Chelyabinsk: Chelyabinskiy Dom pechati. (in Russian).

[6] Smirnov, N. A. (2004). The use of REM to improve the quality of steel. Elektrometallurgiya, no. 2, pp. 34-39. (in Russian).

[7] Goryunov, A.V., Rigin, V.Ye., and Sidorov V.V. (2018) Influence of rare-earth metals on the purity and performance characteristics of cast heat-resistant and corrosionresistant alloy. Metallurg, no. 2, pp. 61-65. (in Russian).

[8] Efimov, V.A. (1976). Casting and crystallization of steel. Moscow: Metallurgiya. (in Russian).

[9] Ershov, G.S. and Bychkov, V.M. (1975). Kinetics of nitride dissolution in the Fe-C-O system. Izvestiya vuzov. Chernaya metallurgiya, no. 4, pp. 72-73. (in Russian).

[10] Zhuchkov, V.I., Gasik M.I., and Sheshukov, O.Yu. (2007). Structure and properties of ferroalloys, in Collection of reports of the Foundry Consulium No.2: Theory and practice of metallurgical processes for the production of ferrous alloys. Chelyabinsk: Chelyabinskiy Dom pechati. (in Russian).

[11] Ryabchikov, I.V., Mizin, V.G., Lyakishev N.P., et al. (1983). Ferroalloys with rare and alkaline earth metals additions. Moscow: Metallurgiya. (in Russian).

[12] Ryabchikov, I.V., Panov, A.G. and Korniyenko A.E. (2007). On the qualitative characteristics of modifiers. Stal', no. 6, pp. 18-32. (in Russian). 
[13] Ryabchikov, I.V., Povolotskiy, V.D., and Solov'yev, N.M. (1994). Structure and properties of fast-cooled modifiers. Liteynoye proizvodstvo, no. 7, pp. 4-7. (in Russian).

[14] Smirnova, V.G., Vyaznikova, E.A., Ovchinnikova, L.A. et al. (2009). The study of the microstructure and chemical composition of the phases of the magnesiumcontaining modifier obtained with different cooling rates. Elektrometallurgiya, no. 4, pp. 33-36. (in Russian).

[15] Gasik, L.N., Ignat'yev, V.S., and Gasik, M.I. (1975). Structure and quality of industrial ferroalloys and master alloys. Kiev: Tekhnika. (in Russian).

[16] Chervyakov, A.N., Kiseleva S.A., and Ryl'nikova, A.G. (1962). Metallographic determination of inclusions in steel. Moscow: Metallurgizdat. (in Russian).

[17] Nakano, H. and Yamanaka, Sh. (1994). Structural study of the solid solutions in a $\mathrm{CaSi}_{2}-\mathrm{LaSi}_{2}$ system. Journal of Solid State Chemistry, vol. 108, pp. 260-266.

[18] Silverman, M.S. and Soulen, J.R. (1963). New high pressure form of calcium disilicide. Journal of Physical Chemistry, vol. 67, pp. 1919-1920.

[19] McWhan, D.B., Compton, V.B., Silverman, M.S. et al. (1967). Crystal structure and superconductivity of a high- pressure phase of $\mathrm{CaSi}_{2}$. Journal of Less-common Metals, vol. 12, pp. 75-76.

[20] Yamanaka, Sh., Komatsu, M., and Inumaru, K. (2012). High pressure synthesis of silicon clathrates and related compounds. Review of high pressure Science and Technology, vol. 22, no. 1, pp. 9-16.

[21] Imai, M. (2012). Structural phase transitions of Zintl-phase silicide $\mathrm{BaSi}_{2}$ and formation of $\mathrm{Si}$ clathrate $\mathrm{Ba}_{8} \mathrm{Si}_{46}$ at high pressures and high temperatures. Review of high pressure Science and Technology, vol. 22, no. 1, pp. 17-25.

[22] Imai, Y. and Watanabe, A. (2010). Assessment of the possibility of the band gap widening of $\mathrm{BaSi}_{2}$ by incorporation of carbon. Intermetallics, vol. 18, no. 8, pp. 14321436. 